\title{
Physical and functional follow-up of tuberculosis patients in initial intensive phase of treatment in Cameroon using the 6-min walk test
}

\author{
Wiliam R. Guessogo ${ }^{1,2}$, Samuel H. Mandengue ${ }^{2,3}$, Peguy B. Assomo Ndemba ${ }^{2}$, Ubald Olinga Medjo ${ }^{4}$, Edmond Ebal Minye', \\ Said Ahmaidi ${ }^{5}$, Abdou Temfemo ${ }^{3,5, *}$ \\ ${ }^{1}$ National Institute of Youth and Sports of Yaounde, Yaounde, Cameroon \\ 2Exercise and Sport Physiology Unit, Faculty of Sciences, University of Douala, Douala, Cameroon \\ ${ }^{3}$ Department of Biological Sciences, Faculty of Medicine and Pharmaceutical Sciences, University of Douala, Douala, Cameroon \\ 4Pneumology Unit, Jamot Hospital of Yaounde, Yaounde, Cameroon \\ 5Laboratoire EA3300 - APERE: Adaptations Physiologiques à l'Exercice et Réadaptation à I'Effort, Faculté des Sciences du Sport, Université de Picardie Jules Verne, Amiens, \\ Cedex, France
}

This study aimed to evaluate functional capacities of Cameroonian tuberculosis (TB) patients in initial intensive phase of treatment using the 6-min walk test (6MWT) and to compare them to an age-matched healthy group. Twenty-eight TB patients newly diagnosed and 19 healthy age-matched peoples participated in the study. Performance parameters were determined using the 6MWT. Anthropometric and cardiorespiratory parameters were measured at baseline and after 6MWT. Two months later, TB patients were submitted to the same evaluation. We found significant differences in anthropometric parameters between the two groups. The baseline cardiorespiratory parameters and performance characteristics of TB patients were lower than control group $(571.7 \pm 121.0 \mathrm{~m}$ vs $841.6 \pm 53.0 \mathrm{~m}, P<0.0001$ for 6 -min walk distance $(6 \mathrm{MWD})$ and $18.1 \pm 2.8 \mathrm{~mL} / \mathrm{kg} / \mathrm{min}$ vs $24.3 \pm 1.2 \mathrm{~mL} / \mathrm{kg} / \mathrm{min}, P<0.001$ for mean $\mathrm{VO}_{2 \text { peak }}$ (peak oxygen consumption). Two months after, significant improvements were noted in anthropometric, cardiorespiratory and performance parameters except for bone mass and $\mathrm{FEV}_{1} / \mathrm{FEV}_{6}$ (forced expiratory volumes in 1 second/6 seconds) ratio. Significant correlations were found between the 2-min walked distance $(P<0.0001$, $r=0.95)$, 4-min walked distance $(P<0.0001, r=0.97)$ and 6MWD. In conclusion, TB patients have impaired physical functional capacity but they improved after 2 months of treatment. 6MWT can be a useful tool in the assessment of physical parameters and cardio-respiratory functional capacity rehabilitation of TB patients during the treatment.

Keywords: Tuberculosis, Physical capacity, Functional capacity, Initial intensive phase, Six-minute walk test

\section{INTRODUCTION}

Tuberculosis (TB) continues to exhibit the highest rate of morbidity and mortality among chronic infections worldwide (Di Naso et al., 2011; Ramos et al., 2006). Each year, 8.9 million of new cases and 1.6 million of deaths are registered (World Health Organization, 2007). The prevalence of TB in developing countries remains high (Noubom et al., 2013). Cameroon recently reported a total of 26,110 cases of TB nationally, with 15,080 new smear-positive cases, corresponding to rates of 124 and 73 per
100,000 populations respectively (Agbor et al., 2015).

TB causes poor ventilation and gas exchange and an overall decline in functional status (Sivaranjini et al., 2010). Furthermore, respiratory diseases as TB results in physical deconditioning, muscle atrophy and, impaired lung function and gas exchange (Croitoru and Bogdan, 2014). The consequences of changes observed in muscle system are lower exercise tolerance, decrease in daily physical activities and impaired quality of life (Croitoru and Bogdan, 2014; Maguire et al., 2009).

TB remains a global public health problem despite the presence
*Corresponding author: Abdou Temfemo (iD http://orcid.org/0000-0002-6449-9512 Department of Biological Sciences, Faculty of Medicine and Pharmaceutical Sciences, University of Douala, Douala, Cameroon

Tel: +333-22-82-7441, Fax: +333-22-82-7844, E-mail: temfemo@hotmail.com Received: May 3, 2016 / Accepted: July 14, 2016
This is an Open Access article distributed under the terms of the Creative Commons Attribution Non-Commercial License (http://creativecommons.org/licenses/by-nc/4.0/) which permits unrestricted non-commercial use, distribution, and reproduction in any medium, provided the original work is properly cited. 
of effective TB pharmacotherapy for more than $50 \mathrm{yr}$ and the use of vaccines for more than $90 \mathrm{yr}$ (Kasozi et al., 2015). Nowadays, TB treatment is done in two phases: an initial intensive phase of two months comprising an association of Ethambutol (E), Isoniazid (H), Rifampicin (R) and Pyrazinamide (Z) (2HRZE), and a continuous phase of four months duration constituted of $\mathrm{R}$ and $\mathrm{H}$ (4RH) (World Health Organization, 2010).

The health recovery follow-up of TB patients is based, either on clinic, radiographic and laboratory examinations, (which often are more expensive for poor populations) or, on subjective declarations with respect to an eventual improvement of their physical capacities. Although, the ability to ambulate for a distance is a quick and inexpensive measure of physical function and an important component of quality of life since it reflects the capacity for undertaking daily activities (Sivaranjini et al., 2010).

In general, functional walk tests are typically administered as a mean of evaluating functional status, monitoring effectiveness of treatment and establishing prognosis (Sivaranjini et al., 2010). The 6-min walk test (6MWT) is widely used in evaluation of exercise capacities in respiratory diseases (Demir and Küçükoğlu, 2015) and other lung diseases (Tonelli et al., 2014). 6MWT gives more advantages because practical and simple, low cost, reproducible and convenient for a group of many patients and only requires ability to walk. 6MWT is a submaximal test used as clinical indicator of the functional capacity in patients of cardiopulmonary diseases (Al Ameri, 2006). This test reflects better the daily life activities than laboratory tests, it is well tolerated by patients (McLaughlin et al., 2009; McLaughlin et al., 2013), and can also be used to evaluate the effects of a treatment administrated. The distance completed by a patient on a flat surface in 6-min walk may be used as a generic one-time measure of functional status or as an outcome measure from a rehabilitation program.

Many studies conducted using pulmonary rehabilitation have shown their efficacy in TB and post-TB patients (Ando et al., 2003; Croitoru and Bogdan, 2014; de Grass et al., 2014; Yoshida et al., 2006). Because of high risk of contamination, little attention has been given to the effects of pulmonary TB in terms of physical disability, whereas physical performances of these patients could provide information on the disease gravity and administered treatment efficacy.

The present study has double objective: (a) To compare the baseline physical characteristics of TB patients with those of agematched group of healthy people and, (b) to evaluate functional capacities of Cameroonian TB patients in initial intensive phase of treatment using the 6MWT.

\section{MATERIALS AND METHODS}

\section{Participants}

The study was conducted in the Jamot Hospital of Yaounde (Cameroon). Twenty-eight new diagnosed patients of smear-positive pulmonary tuberculosis $(\mathrm{TB}+$ ) of both sexes, who have signed a consent form to participate to the study were recruited. Patients were included if they were able to walk, with a respiratory rate $>30$ cycles per minute, a Karnofsky index (IK)> 70 and in- or out-patients. All TB patients started taking medications for the treatment of TB. Nineteen healthy age-matched people from the normal population were chosen as a control for comparison. This longitudinal study was approved by the scientific committee of the hospital. The study was conducted in accordance with the Helsinki Declaration as revised in 1989.

\section{Study design}

General, cardiovascular and pulmonary evaluations as well as the 6MWT were realized at diagnosis and after 2 months by the investigator and an experimented nurse.

\section{General evaluation}

After diagnosis confirmation by a medical doctor, weight, muscle mass (MM) and bone mass (BM) were recorded using a bio-impedance meter scale Tanita BC-532 (Tanita Corp., Tokyo, Japon). The IK was determined by a scale proposed by Karnofsky and Burchenal (1949). The body mass index (BMI) was calculated by dividing the weight in kilogram by the square of the height in meter.

\section{Oxygen saturation and Cardiovascular evaluation}

Oxygen saturation $\left(\mathrm{SpO}_{2}\right)$ and resting heart rate $(\mathrm{HR})$ were measured with an electronic pulse oximeter (ChoiceMMed, OxyWatchC20, Beijing, China). Systolic blood pressure (SBP) and diastolic (DBP) were determined using an electronic blood pressure device (Medisana AG, Neuss, Germany).

\section{Pulmonary evaluation}

This evaluation followed the American Thoracic Society/European Respiratory Society recommendations (Miller et al., 2005). Forced expiratory volumes in 1 second $\left(\mathrm{FEV}_{1}\right)$ and 6 seconds $\left(\mathrm{FEV}_{6}\right)$, and the ratio $\mathrm{FEV}_{1} / \mathrm{FEV}_{6}$ were determined with an electronic peak-flow meter (Piko 6; nSpire Health Inc., Longmont, CO, USA). For each participant, two maneuvers of forced expiratory were realized after a maximal inspiration and the best value was recorded. 


\section{6-min walk test}

The test was performed according to the American Thoracic Society guidelines (ATS Committee on proficiency standards for clinical pulmonary function laboratories, 2002) in a 40-m-long straight hospital corridor, with line-marks every meter. Participants were instructed about the purpose of the test which was to see how far they could walk in 6 min. Participants were instructed to walk from one end to the other, covering as much ground as possible during the allotted time. No verbal encouragement was given during the test only the remaining duration was indicated every minute. The test was self-paced and participant could rest if they so wished. They were allowed to stop, if symptoms of significant distress like chest pain, dizziness or leg cramps occurred. However, they were asked to resume walking as soon as possible if they could. The distance covered was registered at 2, 4, and $6 \mathrm{~min}$. At the end of the $6 \mathrm{~min}$, cardiovascular and pulmonary parameters were again measured. The 6-min walk distance (6MWD) was recorded and the Borg score (rating of perceived exertion, RPE) determined using the modified Borg visual analog scale (Borg, 1982).

The 6MWD was converted in 6-min walk work (6MWW) by multiplying the body weight in kilogram by 6MWD in meter $(\mathrm{kg} / \mathrm{m})$. The mean peak of oxygen consumption $\left(\mathrm{VO}_{2 \text { peak }}\right)$ was calculated using the formula of Ross et al. (2010): $\mathrm{VO}_{2 \text { peak }}(\mathrm{mL} / \mathrm{kg}$ / $\min )=4.948+0.023 \times 6 \mathrm{MWD}(\mathrm{m})$.

\section{Statistical analysis}

Data were analyzed using Statview software (SAS Institute Inc., Cary, NC, USA) and were expressed as mean values \pm standard deviations. Wilcoxon signed rank test was done to compare values obtained at the baseline and two months after, and Mann-Whitney test was used to compare baseline characteristics of TB patients and healthy age-matched group. The repeated measures analysis of variance was used to compare the distances recorded at 2, 4, and $6 \mathrm{~min}$ during the 6MWT and the Fischer Least Significant Difference post hoc test was performed to locate this difference. Pre- and post6MWT measures were also compared using the Wilcoxon rank test. Interaction between parameters was determined using Spearman correlation test. The level of significance was set at $P<0.05$.

\section{RESULTS}

Twenty-eight smear-positive TB patients newly diagnosed (71\% males) and 19 healthy subjects (69\% males) were enrolled in the study. At the time of diagnosis (baseline), except age and height, there were significant differences in all anthropometric parameters between TB patients and healthy people. There were also

Table 1. Comparison of baseline TB patient's characteristics with healthy group, and variation of TB patient's characteristics

\begin{tabular}{|c|c|c|c|}
\hline \multirow{2}{*}{ Characteristic } & \multicolumn{2}{|c|}{ TB patients } & \multirow{2}{*}{ Healthy subjects } \\
\hline & Baseline & 2 Months after & \\
\hline \multicolumn{4}{|l|}{ Anthropometric } \\
\hline Age (yr) & $29 \pm 8$ & - & $28 \pm 3$ \\
\hline Height (cm) & $172.0 \pm 0.1$ & - & $173.7 \pm 8.7$ \\
\hline Weight (kg) & $59.8 \pm 7.9$ & $62.4 \pm 7.9^{* *}$ & $73.7 \pm 11.1^{* * *}$ \\
\hline Body mass index $\left(\mathrm{kg} / \mathrm{m}^{2}\right)$ & $20.2 \pm 2.3$ & $21.1 \pm 2.4^{*}$ & $24.4 \pm 3.0^{* *}$ \\
\hline Muscle mass $(\%)$ & $49.0 \pm 6.4$ & $50.3 \pm 6.6^{*}$ & $67.1 \pm 5.1^{* * *}$ \\
\hline Bone mass $(\%)$ & $2.6 \pm 0.3$ & $2.6 \pm 0.5$ & $3.5 \pm 0.3^{*}$ \\
\hline Karnosky index (\%) & $82.2 \pm 7.0$ & $94.4 \pm 5.8 * * *$ & $100.0 \pm 0 * * *$ \\
\hline \multicolumn{4}{|c|}{ Cardiorespiratory and performance } \\
\hline $\mathrm{SBP}(\mathrm{mmHg})$ & $105 \pm 9$ & $118 \pm 11^{* *}$ & $114 \pm 8^{*}$ \\
\hline $\mathrm{DBP}(\mathrm{mmHg})$ & $67 \pm 9$ & $78 \pm 7^{* *}$ & $70 \pm 5$ \\
\hline $\mathrm{SpO}_{2}(\%)$ & $96.5 \pm 2.5$ & $97.5 \pm 1.1^{*}$ & $98.2 \pm 0.7^{*}$ \\
\hline RHR (bpm) & $97 \pm 15$ & $88 \pm 18^{* * *}$ & $75 \pm 9^{* * *}$ \\
\hline $\mathrm{FEV}_{1}(\mathrm{~L})$ & $1.8 \pm 0.7$ & $2.1 \pm 0.7^{*}$ & $3.0 \pm 0.8^{*}$ \\
\hline $\mathrm{FEV}_{6}(\mathrm{~L})$ & $1.9 \pm 0.8$ & $2.2 \pm 0.7^{*}$ & $3.4 \pm 1.0^{*}$ \\
\hline $\mathrm{FEV}_{1} / \mathrm{FEV}_{6}$ & $0.95 \pm 0.06$ & $0.95 \pm 0.10$ & $0.89 \pm 0.06^{*}$ \\
\hline $6 \mathrm{MWD}(\mathrm{m})$ & $571.7 \pm 121.0$ & $639.0 \pm 99.7^{* *}$ & $841.6 \pm 53.0^{* * *}$ \\
\hline $\mathrm{VO}_{2 \text { peak }}(\mathrm{mL} / \mathrm{kg} / \mathrm{min})$ & $18.1 \pm 2.8$ & $19.7 \pm 2.3^{*}$ & $24.3 \pm 1.2^{* *}$ \\
\hline $6 \mathrm{MWW}(\mathrm{kg} / \mathrm{m})$ & $34,441 \pm 10,187$ & $40,173 \cdot 6 \pm 9,841.8^{* *}$ & $61,961.2 \pm 9,522.3^{* * *}$ \\
\hline RPE & $2.9 \pm 1.1$ & $2.1 \pm 1.1^{* *}$ & $1.4 \pm 0.3^{*}$ \\
\hline
\end{tabular}

Values are presented as mean \pm standard deviation.

TB, tuberculosis; $\mathrm{SBP}$, systolic blood pressure; DBP, diastolic blood pressure; $\mathrm{SpO}_{2}$, oxygen saturation; $\mathrm{RHR}$, resting heart rate; $\mathrm{FEV}_{1}$, forced expiratory volume 1 second; FEV $\mathrm{6}_{6}$ forced expiratory volume 6 seconds; $6 \mathrm{MWD}$, 6-min walk distance; $6 \mathrm{MWW}$, 6-min walk work; $\mathrm{VO}_{2 \text { peak, }}$, peak oxygen consumption; $\mathrm{RPE}$, rating of perceived exertion.

${ }^{*} P<0.05 .{ }^{* *} P<0.01 .{ }^{* * *} P<0.001$. 
Table 2. Pre- and posttest cardiorespiratory values of tuberculosis patients

\begin{tabular}{|c|c|c|c|c|}
\hline \multirow{2}{*}{ Variable } & \multicolumn{2}{|c|}{ Baseline } & \multicolumn{2}{|c|}{2 Months after } \\
\hline & Pre-6MWT & Post-6MWT & Pre-6MWT & Post-6MWT \\
\hline SBP & $105 \pm 9$ & $110 \pm 12^{*}$ & $118 \pm 11$ & $120 \pm 10$ \\
\hline DBP & $67 \pm 9$ & $69 \pm 10$ & $78 \pm 7$ & $83 \pm 11^{* *}$ \\
\hline $\mathrm{SpO}_{2}$ & $96.5 \pm 2.5$ & $93.3 \pm 4.7^{* * *}$ & $97.5 \pm 1.1$ & $95.2 \pm 3.8^{* *}$ \\
\hline $\mathrm{HR}$ & $97 \pm 15$ & $147 \pm 19 * * *$ & $88 \pm 18$ & $150 \pm 21^{* * *}$ \\
\hline $\mathrm{FEV}_{1}$ & $1.8 \pm 0.7$ & $1.7 \pm 0.7$ & $2.1 \pm 0.7$ & $2.1 \pm 0.8$ \\
\hline $\mathrm{FEV}_{6}$ & $1.9 \pm 0.8$ & $1.8 \pm 0.8$ & $2.2 \pm 0.7$ & $2.2 \pm 0.8$ \\
\hline $\mathrm{FEV}_{1} / \mathrm{FEV}_{6}$ & $0.95 \pm 0.06$ & $0.93 \pm 0.10$ & $0.95 \pm 0.10$ & $0.96 \pm 0.05$ \\
\hline
\end{tabular}

GMWT, 6-min walk test; SBP, systolic blood pressure; DBP, diastolic blood pressure; $\mathrm{SpO}_{2}$, oxygen saturation; $\mathrm{HR}$, heart rate; $\mathrm{FEV}_{1}$, forced expiratory volume 1 second; FEV forced expiratory volume 6 second.

${ }^{*} P<0.05 .{ }^{* *} P<0.01 .{ }^{* *} P<0.001$

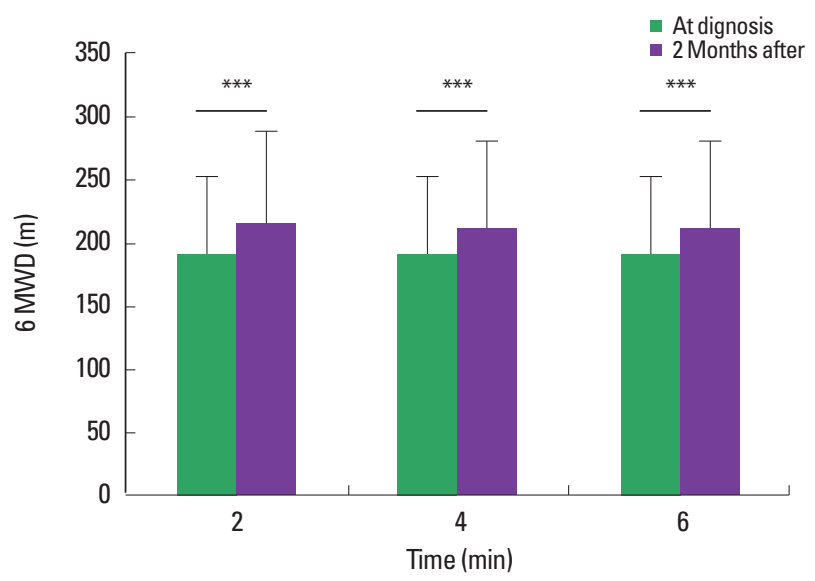

Fig. 1. Intermediate distances covered each 2 min during tests. 6MWD, 6-min walk distance. ${ }^{* *} P<0.01 .{ }^{* *} P<0.001$.

significant differences in baseline cardiorespiratory characteristics between TB patients and healthy people. The performance characteristics were lower in the TB patients compared to healthy group $(571.7 \pm 121.0 \mathrm{~m}$ vs $841.6 \pm 53.0 \mathrm{~m}, P<0.0001$ for $6 \mathrm{MWD}$ and $18.1 \pm 2.8 \mathrm{~mL} / \mathrm{kg} / \mathrm{min}$ vs $24.3 \pm 1.2 \mathrm{~mL} / \mathrm{kg} / \mathrm{min}, P<0.001$ for mean $\mathrm{VO}_{2 \text { peak }}$. Baseline characteristics of participants and variations of TB patient's characteristics are presented in Table 1.

We recorded significant changes in anthropometric, cardiorespiratory and performance parameters measured in TB patients. Only the $\mathrm{BM}$ and the $\mathrm{FEV}_{1} / \mathrm{FEV}_{6}$ ratio did not change over the initial intensive phase of treatment. The rate of anthropometric and performance variations were $4.4 \%(P<0.01)$ for weight, $4.5 \%$ $(P<0.05)$ for BMI, $2.7 \%(P<0.05)$ for MM and $14.8 \%$ $(P<0.001)$ for IK, $11.8 \%(P<0.001)$ for $6 \mathrm{MWD}$, and $8.8 \%$ $(P<0.01)$ for mean $\mathrm{VO}_{2 \text { peak. }}$.

Concerning the difficulty of the effort, the RPE was higher in TB patients than healthy group $(2.9 \pm 1.1$ vs $1.4 \pm 0.3$, respective-
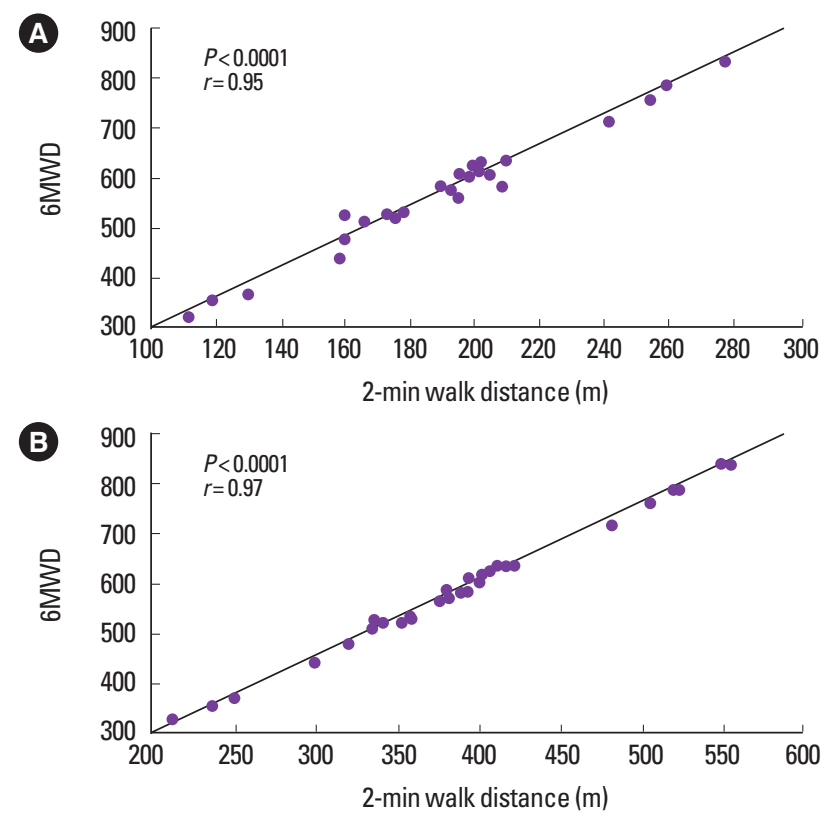

Fig. 2. Correlations between intermediate distances (A: 2-min walk distance; $B$ : 4-min walk distance ) and total distance covered. 6MWD, 6-min walk distanc.

ly, $P<0.01)$. But 2 months later, there was a drop of RPE in TB patients from the baseline to the end of the initial intensive phase of treatment $(2.9 \pm 1.1$ vs $2.1 \pm 1.1$, respectively, $P<0.05)$.

Table 2 shows the pre- and post-6MWT variations of cardiorespiratory parameters at baseline and 2 months after initiation of treatment. At baseline, there are significant changes in SBP $(P<0.05), \mathrm{SpO}_{2}(P<0.001)$, and $\mathrm{HR}(P<0.0001)$ after the test. Two months later, we recorded changes in $\mathrm{DBP}(P<0.001), \mathrm{SpO}_{2}$ $(P<0.001)$, and HR $(P<0.0001)$. The respiratory parameters $\left(\mathrm{FEV}_{1}, \mathrm{FEV}_{6}\right.$, and $\left.\mathrm{FEV}_{1} / \mathrm{FEV}_{6}\right)$ did not change significantly.

The distances covered by TB every 2 min during the 6MWT are presented in Fig. 1. We noted that neither at diagnosis nor 2 
months later, there was no difference between intermediate distances covered each 2 min during each 6MWT. But, significant differences existed between the distance covered at diagnosis and that after 2 months during every 2 min of walk $(P<0.0001)$.

Fig. 2 shows interaction between distances covered after 2 - and 4-min walking with the total distance covered over the $6 \mathrm{~min}$ (6MWD). Strong and significant correlations are registered between the 2-min walk distance $(P<0.0001, \mathrm{r}=0.95)$ and 4-min walk distance $(P<0.0001, \mathrm{r}=0.97)$ with 6MWD.

\section{DISCUSSION}

The baseline characteristics of TB patients are lower than those of a healthy age-matched group of people. However anthropometric, cardiorespiratory and performance parameters of $\mathrm{TB}$ patients improved after the initial intensive phase of treatment. This study is the first conducted among TB patients in Cameroon with this aim, and the results can enable the medical doctors to take a better and objective decision during the follow-up and the management of their patients.

The reports on exercise testing and physical functional capacity evaluation in people with chronic respiratory failure as a consequence of TB are very rare, because of the high risk of contamination. Sivaranjini et al. (2010) have already shown that there was a significant difference of physical functional capacity between groups of adult normal persons and patients with TB sequelae. The TB sequelae group had a poor aerobic capacity justifying the great impact of TB sequelae on cardiorespiratory endurance. The results of the present study corroborated with the finding of Sivaranjini et al. (2010) (Table 1). Furthermore, the 6MWT has been reported to be important in the objective evaluation in functional exercise capacity in pulmonary rehabilitation (Adedoyin et al., 2010). The baseline average 6MWD of TB patients was significantly lower than that of healthy age-matched group $(P<0.001)$. Comparable results were also found in a couple of studies (Ramos et al., 2006; Sivaranjini et al., 2010) and demonstrate the high incidence of $\mathrm{TB}$ on physical functional capacity of patients.

When comparing the 6MWD of TB patients in the present study with that of $\mathrm{TB}$ patients in few previous published studies, we realized that patients in our study had better physical performance. For instance, the baseline average 6MWD in the present study was $571.7 \pm 121.0 \mathrm{~m}$, better than that obtained by Adedo-

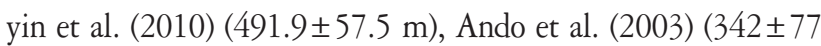
$\mathrm{m})$, Godoy et al. (2012) (525.3 $\pm 109.0 \mathrm{~m})$, and Yoshida et al. (2006) ( $467 \pm 65 \mathrm{~m})$. The differences could be attributed to age, sex or demographic parameters of the studied populations and, suggests the fact that in each context, for a better interpretation of results, specific values of 6MWD should be provided.

The results of the present study showed significant improvement of anthropometric, cardiorespiratory and performance parameters during the initial intensive phase of treatment, except $\mathrm{BM}$ and $\mathrm{FEV}_{1} / \mathrm{FEV}_{6}$ ratio. These findings suggest the effectiveness of the proposed treatment. According to respiratory parameters, Maguire et al. (2009) have already obtained that $\mathrm{FEV}_{1}$ and forced vital capacity (FVC) changed over time, with both increasing from 0 to 2 months $(P<0.001)$ and 2 to 6 months $(P<0.001)$, when evaluating the impact of pulmonary $\mathrm{TB}$ on lung function. Concerning the 6MWD, we noted an improvement of the distance completed after 2 months by $11.8 \%(P<0.001)$. This improvement was confirmed the IK $(P<0.001), \mathrm{SpO}_{2}(P<0.05)$, $\mathrm{FEV}_{1}$ and $\mathrm{FEV}_{6}(P<0.05), 6 \mathrm{MWW}(P<0.001)$, and mean $\mathrm{VO}_{2}$ peak $(P<0.01)$. The improvement rate of $6 \mathrm{MWD}$ was similar to that of Maguire et al. (2009) who obtained a rate of $12.3 \%$, and justify the amelioration of the exercise tolerance of TB patients. Yoshida et al. (2006) examined whether exercise training using nontreadmill walking is effective for the improvement of exercise performance of patients with pulmonary TB sequelae and showed that there was no change in pulmonary function $\left(\mathrm{FEV}_{1} / \mathrm{FVC}\right)$ but, there was an improvement of $\mathrm{VO}_{2}$ peak after 2 weeks of daily walking exercise training.

Despite the fact that in the present study, there was no exercise training, the results are in accordance with those of Yoshida et al. (2006). Previous study concluded that it seems not necessary to submit patients suffering from pulmonary TB to pulmonary rehabilitation (Hall and De Charmoy, 2002). Nevertheless, in contrary with our study, there was no $\mathrm{SpO}_{2}$ variation after 2 weeks, may be because of the short duration of the exercise training. Exercise training seems not important in the improvement of pulmonary function of TB patients, since the patients of the intervention group in the study of de Grass et al. (2014) did not experience any variation of $\mathrm{FEV}_{1}$ and $\mathrm{FVC}$ as far as exercise tolerance compared to those of control group.

In the present study, the resting (pre-) cardiorespiratory parameters of the participants were compared with the post-6MWT cardiorespiratory responses (Table 2). There were no significant differences in the mean respiratory parameters of the participants following 6MWT compared with the pre-6MWT values. Because of their health status, the walking speed was not sufficient to induce lung function changes during the test. That is the reason why, during the test, the patients were not tired and this finding 
is in line with that of Singh et al. (1994), where patients were not tired at the end of the shuttle walking. In the study of Yoshida et al. (2006), no pulmonary function variation was also registered in patients with TB sequelae after 2-week exercise training. Furthermore, we recorded significant decrease of $\mathrm{SpO}_{2}$ between pre- and posttests $(P<0.001)$. This result is explained by the fact that patients with pulmonary TB sequelae have low oxygen venous pressure as result of oxygen transport limitation (Yamamoto, 1996). Concerning the blood pressure, the present study showed that SBP changed only at baseline $(P<0.05)$ and the DBP only after 2 months $(P<0.01)$. Adedoyin et al. (2010) obtained significant variations of SBP and DBP following 6MWT in pulmonary TB patients but the reasons for these changes of pressures were not explained. They concluded that the 6MWT could be useful for the assessment of the cardiovascular parameters of TB patients.

As recommended (ATS Committee on proficiency standards for clinical pulmonary function laboratories, 2002), we recorded distances at periods 0-2 $\mathrm{min}, 2-4 \mathrm{~min}$, and 4-6 min, to evaluate the fatigability of TB patients (Fig. 1). The results revealed that there was no significant difference between distances covered in the three periods at baseline and 2 months after. We suggest that TB patients completed the test with a constant speed and without additional fatigue. The 6MWT seems not to be an appropriated test to assess fatigability in TB patients. But in Fig. 2, we found significant correlations between distances covered at $2 \mathrm{~min}$ and 6MWD ( $\mathrm{r}=0.95, P<0.0001)$, and the distance covered at $4 \mathrm{~min}$ and 6MWD $(r=0.97, P<0.0001)$. This result supposes that the distance walked at 2 min reflects the $6 \mathrm{MWD}$. Then, we can use the 2-min walk test in the assessment of the exercise tolerance in TB patients. Similar results have already been reported by Negm et al. (2012) in patients with chronic obstructive pulmonary disease (COPD), who found significant correlations between distance walked in $2 \mathrm{~min}$ and $6 \mathrm{~min}$. These authors concluded that the 2-min walk test is valid, practical, simple and well-tolerated for the assessment of exercise capacity in patients with COPD.

In conclusion, this study provides information on the baseline physical functional capacity of TB patients and their recovery during the initial intensive phase of treatment. The 6MWT can detect physical capacity changes among TB patients during the treatment, then, it may be useful in the assessment of physical functional capacity of TB patients. The 2-min walk test is efficient in the assessment of the exercise tolerance in TB patients. The sample size of this study can limit the generalization of the results.

\section{CONFLICT OF INTEREST}

No potential conflict of interest relevant to this article was reported.

\section{ACKNOWLEDGMENTS}

The authors thank the Director of the Jamot Hospital and the staff of the Pneumology Unit for their collaboration.

\section{REFERENCES}

Adedoyin RA, Erhabor GE, Ojo OD, Mbada CE, Awotidebe TO, Obaseki DO, Awofolu OO. Assessment of cardiovascular fitness of patients with pulmonary tuberculosis using six minute walk test. TAF Prev Med Bull 2010;9:99-106

Agbor AA, Bigna JJ, Plottel CS, Billong SC, Tejiokem MC, Ekali GL, Noubiap JJ, Toby R, Abessolo H, Koulla-Shiro S. Characteristics of patients co-infected with HIV at the time of inpatient tuberculosis treatment initiation in Yaoundé, Cameroon: a tertiary care hospital-based cross-sectional study. Arch Public Health 2015;73:24.

$\mathrm{Al}$ Ameri HF. Six minute walk test in respiratory diseases: a university hospital experience. Ann Thorac Med 2006;1:16-19.

Ando M, Mori A, Esaki H, Shiraki T, Uemura H, Okazawa M, Sakakibara $\mathrm{H}$. The effect of pulmonary rehabilitation in patients with post-tuberculosis lung disorder. Chest 2003;123:1988-1995.

ATS Committee on proficiency standards for clinical pulmonary function laboratories. ATS statement: guidelines for the six-minute walk test. Am J Respir Crit Care Med 2002;166:111-117.

Borg GA. Psychophysical bases of perceived exertion. Med Sci Sports Exerc 1982;14:377-381.

Croitoru A, Bogdan MA. Evidences related to pulmonary rehabilitation in the respiratory pathology. Pneumologia 2014;63:88-90, 92-95.

de Grass D, Manie S, Amosun SL. Effectiveness of a home-based pulmonary rehabilitation programme in pulmonary function and health related quality of life for patients with pulmonary tuberculosis: a pilot study. Afr Health Sci 2014;14:866-872.

Demir R, Küçükoğlu MS. Six-minute walk test in pulmonary arterial hypertension. Anatol J Cardiol 2015;15:249-254.

Di Naso FC, Pereira JS, Schuh SJ, Unis G. Functional evaluation in patients with pulmonary tuberculosis sequelae. Rev Port Pneumol 2011; 17:216-221

Godoy MD, Mello FC, Lopes AJ, Costa W, Guimarães FS, Pacheco AG, Castanho IA, Menezes SL. The functional assessment of patients with pulmonary multidrug-resistant tuberculosis. Respir Care 2012;57: 
1949-1954.

Hall M, De Charmoy S. Exercise capacity in pulmonary tuberculosis. S Afr J Physiother 2002;58:9-14

Karnofsky DA, Burchenal JH. The clinical evaluation of chemotherapeutic agents in cancer. In: MacLeod CM, editor. Evaluation of chemotherapeutic agents. New York: Columbia University Press; 1949. p. 191-205

Kasozi S, Clark J, Doi SA. Intermittent versus daily pulmonary tuberculosis treatment regimens: a meta-analysis. Clin Med Res 2015; 13:117138.

Maguire GP, Anstey NM, Ardian M, Waramori G, Tjitra E, Kenangalem E, Handojo T, Kelly PM. Pulmonary tuberculosis, impaired lung function, disability and quality of life in a high-burden setting. Int J Tuberc Lung Dis 2009;13:1500-1506.

McLaughlin VV, Badesch DB, Delcroix M, Fleming TR, Gaine SP, Galiè N, Gibbs JS, Kim NH, Oudiz RJ, Peacock A, Provencher S, Sitbon O, Tapson $\mathrm{VF}$, Seeger W. End points and clinical trial design in pulmonary arterial hypertension. J Am Coll Cardiol 2009;54(1 Suppl):S97-107.

McLaughlin VV, Gaine SP, Howard LS, Leuchte HH, Mathier MA, Mehta S, Palazzini M, Park MH, Tapson VF, Sitbon O. Treatment goals of pulmonary hypertension. J Am Coll Cardiol 2013;62(25 Suppl):D73-81.

Miller MR, Hankinson J, Brusasco V, Burgos F, Casaburi R, Coates A, Crapo R, Enright P, van der Grinten CP, Gustafsson P, Jensen R, Johnson DC, MacIntyre N, McKay R, Navajas D, Pedersen OF, Pellegrino R, Viegi G, Wanger J; ATS/ERS Task Force. Standardisation of spirometry. Eur Respir J 2005;26:319-338.

Negm MF, Abdalla ME, Almahdy MA. Study of 2-min walk test and 15step exercise oximetry test in the assessment of exercise tolerance in Egyptian patients with chronic obstructive pulmonary disease. Egypt J Chest Dis Tuberc 2012;61:291-296
Noubom M, Nembot FD, Donfack H, Mfin PS, Tchasse F. Characteristics of TB patients in west Cameroon: 2000-2009. Pan Afr Med J 2013;16:39. Ramos LM, Sulmonett N, Ferreira CS, Henriques JF, de Miranda SS. Functional profile of patients with tuberculosis sequelae in a university hospital. J Bras Pneumol 2006;32:43-47.

Ross RM, Murthy JN, Wollak ID, Jackson AS. The six minute walk test accurately estimates mean peak oxygen uptake. BMC Pulm Med 2010; 10:31.

Singh SJ, Morgan MD, Hardman AE, Rowe C, Bardsley PA. Comparison of oxygen uptake during a conventional treadmill test and the shuttle walking test in chronic airflow limitation. Eur Respir J 1994;7:20162020.

Sivaranjini S, Vanamail P, Eason J. Six minute walk test in people with tuberculosis sequelae. Cardiopulm Phys Ther J 2010;21:5-10.

Tonelli AR, Wang XF, Alkukhun L, Zhang Q, Dweik RA, Minai OA. Heart rate slopes during 6-min walk test in pulmonary arterial hypertension, other lung diseases, and healthy controls. Physiol Rep 2014; 2(6). pii: e12038.

World Health Organization. Estimated incidence, prevalence and TB mortality: Geneva: World Health Organization; 2007.

World Health Organization. Treatment of tuberculosis: guidelines. Geneva: World Health Organization, 2010.

Yamamoto T, Nagao K, Okada O, Yasuda J, Tanabe N, Kato K, Kuriyama T. Relation of pulmonary hemodynamics and ventilation to tissue hypoxia during exercise in patients with tuberculosis sequelae. Kekkaku 1996;71:331-337.

Yoshida N, Yoshiyama T, Asai E, Komatsu Y, Sugiyama Y, Mineta Y. Exercise training for the improvement of exercise performance of patients with pulmonary tuberculosis sequelae. Intern Med 2006;45:399403. 